
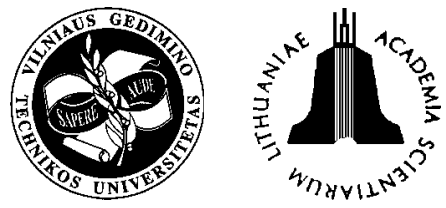

ISSN 1648-4142 TRANSPORT

\title{
OPTIMIZATION OF TECHNOLOGICAL PROCESSES AT THE TERMINAL
}

\author{
Danutė Bagdonienè ${ }^{1}$, Skirmantas Mazūra ${ }^{2}$ \\ ${ }^{1}$ Dept of Mathematical Statistics, Vilnius Gediminas Technical University, \\ Sauletekioal.11,LT-10223Vilnius-40,Lithuania.E-mail: lsaulis@fm.lt \\ ${ }^{2}$ Dept of Transport Management, Vilnius Gediminas Technical University, \\ Plytiness. 27, LT-10105, Vilnius-40, Lithuania.E-mail: skirma@centras.lt
}

Received 2004-01-11; accepted 2004-04-15

\begin{abstract}
The reliability of terminal operation is analysed by statistical methods based on the collected statistical data. Major estimates are made on a specified credibility level (probability). When the terminal is highly reliable and the interaction between transport facilities, freight senders and recipients is efficient, the work with minimum reserves and lower storage costs may be planned. The optimization problem of managing the interaction of railway and road transport at the seaport terminals is considered and the number of transfers to the port or approach roads is determined.
\end{abstract}

Keywords: terminal; technological interaction; interaction point.

\section{Introduction}

A terminal is the end point where all available transport facilities of two or more routes interact and all the operations associated with them are performed.

Freight transportation by railway to a terminal often involves carriage by road. Therefore, railroad terminals also have road terminal equipment. The roads of particular enterprises are provided with special equipment (depending on the freight type).

One of the most important terminal parts is a railway sorting yard. Trains may be re-formed there by grouping the wagons according to their destination. This is done using locomotives or a gravity hump for wagons. The trains are re-formed in a similar way for various recipients who unload them. For smaller loads spacious storehouses are needed.

In managing these operations a large spread of the points for cargo flow formation and distribution, the variety of the handled cargoes and the amount of cargo transferred from one transport facility to another play an important role. The main functions of terminals are associated with the coordination of operation of various transport facilities depending on their relationships with particular branches of economy and technological improvement of freight carriage by various transport facilities.

By providing the above technological level, a steady pace of transport facilities interaction, efficient freight handling with minimum idle time of wagons, ships, trucks and planes as well as the efficient use of transfer points and loading, sorting, storing and other facilities may be achieved.

Only the coordinated operation of railway stations, transport facilities, seaports, approach roads and other technological chains of a general transportation conveyor system may ensure the efficient work of terminals.

An integrated technological process is perceived as an organization system embracing the operation of all interacting transport facilities at the terminal providing efficient transportation. The total labour input of the staff of various transport sectors including freight carriage by sea, railway, road, etc. makes a basis of the integrated technology.

To ensure efficient technological cooperation the following problems should be solved: general scheduling of operations with the groups of wagons and trains at the stations and on approach roads, the coordination of general technology with freight routing and making up of ships and trains, a rhythmical pace of freight loading and unloading (in time and space) and traffic schedules for the total route of freight transportation (from shipment to destination point) should be provided.

An important role in developing this form of technological cooperation is played by the implementation of transportation without cargo transfer and the use of containers and packaging.

Now, freight carriage without cargo transfer by railway, ferries, trailers, containers, etc. is widely used.

The interaction of various transport facilities in 
the network of transportation is considered in a number of papers [1-4]. Modelling of cargo loading operations at the terminal is discussed in $[5,6]$, while the interaction of transport facilities at a single terminal is analysed in [7, 8]. However, one can hardly find in the literature the analysis of the problem of optimizing technological operations at a terminal where various transport facilities interact. In the presented paper an effort is made to deal with this problem trying to find the ways of the above process optimization.

\section{Major stages of joining the operations of various transport facilities into a single technological process}

A joint technological process may be achieved when the following work is performed:

- the performance of the interaction points at the terminal is studied and major obstacles preventing their efficient operation are identified and eliminated (sometimes, large investments are not even needed for it). At this stage major sources of information are calendar plans of interacting transport facilities; traffic schedules of transport facilities; formation plans of ships and trains; data about terminal equipment and its usage; specified and actual standards of each service provided to transport facilities; data on traffic flows and advanced methods of operation and other data associated with a particular terminal;

- the work of cargo transfer at the terminal is efficiently distributed by using economic and mathematical methods between the interaction points and their separate channels according to their specialization. The operations of transport facilities are scheduled, the masses of shunting rolling stocks and ships are determined and cargo transfer operations are specified.

The optimization of the specific interaction at the terminal points is chosen based on technical and economic calculations (minimization of overall expenses) in accordance with the run and repetitive cargo handling as well as with the truck run including bringing the cargoes in and out the stations and seaports.

Organizing the interaction of the main railway transport and the terminal, the schedule of train shunting is made. The number of shunting rolling stocks is determined as follows:

$$
N=\frac{m_{v i d} g_{b r}\left(1+t_{\beta} \gamma_{s}\right)}{Q_{p e r}}
$$

where $m_{v i d}$ - average number of wagons per day departing from the main station to the next one; $g_{b r}-$ wagon mass brutto; $t_{\beta}$ - standard deviation equal to 1,$65 ; \gamma_{s}$-variability coefficient of wagons flow per day.
In the investigation it has been found that

$$
\gamma_{s}=134,58 m_{\text {vid }}^{-0,347} \text {. }
$$

At this calculation stage the concerted actions of cargo transfer and transport forwarding play a vital role. But in fact cargo transfer at the terminal is often delayed because of the lack of the required number of trucks, wagons or ships. Therefore, optimal volumes of cargo to be transferred are specially calculated for any particular case taking into account the capacity of the terminal.

Technological schedules are made for each element of the terminal and loading-unloading equipment and documents processing schedules are derived for transfer points. In developing simple technological schedules the possibilities of time coupling of operations allowing the reduction of operational time and rolling stock efficiency increase were revealed.

The duration of shunting, technical and commercial operations of ships, wagons and trucks is determined according to specifications. If the latter has not been developed, the time of operations is found by statistical methods based on the available data.

In general the time of handling a single transport facility is determined from the formula:

$$
t_{t r . v}^{k r}=t_{p a r}+t_{u \check{z}}+t_{p a k}+t_{p e r}+\sum t_{l a u},
$$

here $t_{p a r}, t_{u \check{z}}$-time of preliminary and final operations, $\mathrm{h} ; t_{\text {pak }}$ - loading (unloading) time of a single transport facility or its group, $\mathrm{h} ; t_{\text {per }}$ - service interruption time during loading (unloading), h; $\sum t_{l a u}$ - total waiting time, h.

In some cases, for example, handling a railway route in parts in a port harbour we get:

$$
\begin{aligned}
& t_{\text {mař }}^{k r}=t_{p a k} x_{p . n}+\left(t_{p d}+t_{n u}\right) x_{p . n}+N_{m} t_{p a p}+ \\
& \sum t_{a t-i \check{s}}+\sum t_{l a u}
\end{aligned}
$$

here $t_{p a k}=m_{p . n} q \varepsilon / \sum p_{i_{p e r}} ; m_{p . n}-$ number of wagons in a single driving up; $q$ - wagon lifting power, $\mathrm{t} ; \varepsilon$ - lift coefficient; $\sum_{i=1}^{k} p_{i_{p e r}}-$ total capacity of cargo transfer equipment at the $i$-th interaction point used for wagon loading and unloading, $\mathrm{t} / \mathrm{h} ; x_{p . n}$ - number of wagon driving up distributions; $t_{p d}, t_{n u}$ - time of wagons driving up and out, h; $N_{m}$-number of wagons on the route; $t_{\text {pap }}$-average time of extra operations for one wagons, h; $t_{a t-i \check{s}}$ - time of arrival at and departure from the station on the route, $\mathrm{h} ; k$-number of hoisting mechanisms installed in a harbour.

Time of ship handling (servicing) is:

$$
t_{k r . l}=\frac{Q}{k_{\text {maž }} \sum_{i=1}^{n} p_{i_{p e r}}}+t_{p a r}+t_{p e r}+t_{u \check{z}}+\sum t_{l a u},
$$


where $Q$ - transferred cargo, $\mathrm{t} ; k_{m a z ̌}$ - capacity reduction coefficient of transfer mechanisms concentrated to service one ship. For rough calculations $k_{m a z ̌}$.

By outlining the standard cycles of handling ships, wagons and trucks, it is possible to transfer developing an integrated technological process. However, first it is necessary to check if major conditions of transport facilities interaction are observed.

The intervals of calculating transport facility arrival and departure from the interaction points should correspond to the interval of their technological processing.

$$
t_{j}^{p a k} \leq I_{j}^{a t}, t_{j}^{i \check{s}} \leq I_{j}^{i \check{s}},
$$

where $t_{j}^{p a k}, t_{j}^{i \check{s}}$ - time of technological operation of loading (unloading) the $i$-th transport facility (or a group of facilities); $I_{j}^{a t}, I_{j}^{i \check{s}}$ - calculation interval of the $j$-th type of transport facilities. The calculation interval is determined from the expression:

$$
\bar{I}_{j}^{a t}=\frac{I_{j}^{\min }+\bar{I}_{j}}{2},
$$

where $I_{j}^{\min }, \bar{I}_{j}$-minimum and average intervals of the arrival and departure of the $j$-th transport facility, h.

The average arrival interval is obtained by the formula:

$$
\left.\begin{array}{r}
I_{l}=\frac{T_{k a r} Q_{l} \varepsilon_{l}}{\sum Q_{m i \check{s}}} \\
\bar{I}_{g}=\frac{g_{v} \varepsilon_{v} N_{m} T_{k a r}}{\sum Q_{m i \check{s}}}
\end{array}\right\}
$$

here $T_{k a r}$ - time of joint operation of railway and sea transport, days; $Q_{l}$ - lifting power of a standard ship (rolling stock), $\mathrm{t} ; \varepsilon_{l}$ - lift coefficient of a ship (wagon); $\sum Q_{m i s}$ - transportation by mixed transport facilities in a considered period of time, $\mathrm{t} ; N_{m}$ - number of wagons on a route; $g_{v}$ - average lifting power of a wagon, $\mathrm{t}$.

Mass of cargo $Q_{i}$ delivered to the $i$-th interaction point during a certain period of load transfer should not exceed the capacity of the hoisting equipment, approach roads, storage areas, shunting facilities or limiting factors $P_{i}$ in a particular field of load transfer operations, i.e. $Q_{i}<P_{i}$.

Calendar plans of the arrival of loaded and empty rolling stocks of the $S$-th and $S+1$-th transport facilities at the $i$-th interaction point should be synchronized with the shipment of goods, corresponding to its pace. For example, before starting the handling of a ship the first group of wagons should be gathered and put on the transfer road section. Other groups of wagons should be brought depending on the time needed to service the first group $\left(H_{1}\right)$, i.e. $t_{1}=H_{1} ; t_{2}=t_{1}+t_{t r . v}^{k r} ; t_{3}=t_{1}+$ $2 t_{t r . v}^{k r}$. An empty transport facility of the same tonnage as that of the cargo delivered by $S+1$ transport facility is brought at an interaction point by the $S$-th transport facility, i.e. $Q_{S}^{t u \breve{s}} \leftrightarrow Q_{S+1}^{k r}$.

The conditions of interaction of various transport facilities may be formulated in the following way: the tonnage of the empty $S$-th transport facility should correspond to the cargo mass in the storage areas.

Organizing the interaction of the main railway transport facilities and terminal transport, the number of special roads for trains receiving and dispatching is obtained from the formula:

$$
m_{p r .-i \check{s}}^{k r}=\frac{\left(N_{a t} t_{u \check{z} . a t}+N_{i \check{s} t} t_{u \check{z} . i \check{s}}\right)\left(1+\beta_{p}\right)}{24-\sum T_{\text {past }}},
$$

here $N_{a t}, N_{i \check{s}}$ - a number of transfers after the arrival and shipment, respectively; $t_{u \check{z} . a t}, t_{u z ̌ . i \check{~}}$ - time on the special roads after the arrival and shipment; $\beta_{p}-$ coefficient of equipment failures; $\beta_{p}=0,01 ; \sum T_{\text {past }}$ - time on the road performing operations not related to traffic.

The number of rolling stocks arriving at the terminal with the specified probability is calculated by the formula:

$$
N_{a t}=\frac{\left(\bar{m}_{k r}+t_{\beta} \sigma_{m}\right) g_{b r}}{Q_{p e r}},
$$

here $\sigma_{m}$ - mean square deviation of wagons flow from the real one; $\bar{m}_{k r}$-average number of loading routes at the station.

Time of receiving-dispatching routes occupancy by arriving wagons:

$$
t_{u \check{z} . k}=t_{t . o}^{p}+t_{\text {lauk.ǐsf }}+t_{\text {per }}^{l},
$$

here $t_{t . o}^{p}$-time of technological operation in handling rolling stocks at the receiving/dispatching terminal: for medium-size network, $t_{t . o}^{p}=0,5-1,0 \mathrm{~h} ; t_{\text {lauk.išf }}-$ average waiting time of train breaking up; $t_{p e r}^{l}-$ time of track occupancy when rolling stocks are moved to pulling out tracks, h:

$$
t_{p e r}^{l}=\left(a+b \frac{\bar{m}_{k r}}{N_{a t}}\right) \frac{1}{60},
$$

here $a$ and $b$-coefficients depending on the distance of traffic:

$a=0,5+0,0016 l ; b=0,016+0,000068 l,(0<l \leq 500)$,

$b=0,030+0,000040 l,(500<l \leq 2000)$, 
$l$ - distance covered by moving the trains to another track, $\mathrm{m}$ :

$$
l=\frac{\bar{m}_{k r}}{N_{a t}} l_{v},
$$

$l_{v}$ - wagon length, $\mathrm{m}$.

Waiting time of rolling stock breaking up is:

$$
t_{\text {lauk.išf }}=\frac{12 \rho_{l}^{2}\left(\gamma_{p e r}^{2}+\gamma_{i \check{s} . p}^{2}\right)}{N_{a t}\left(1-\rho_{l}\right)},
$$

here $\rho_{l}$-load of shunting locomotives in making and breaking up trains and making up a group of wagons; $\gamma_{p e r}, \gamma_{i s ̌ p}-$ variability coefficients of rolling stock arrival intervals $(0,4-0,8)$ and breaking up/making up operations $(0,2-0,4)$.

Load of shunting locomotives is:

$$
\rho_{l}=\frac{N_{a t}\left(t_{i \text { isfor }}+t_{\text {for }}^{\text {per }}\right)+\sum_{i=1}^{n} x_{i} t_{\text {for. } i}}{M_{l}\left(1440-\sum T_{\text {past }}\right)},
$$

here $M_{l}$ - number of shunting locomotives; $x_{i}-$ number of wagon groups brought in the $i$-th shunting region; $t_{\text {for. } i}$ - time of making up the $i$-th group of wagons; $t_{i \check{s} \text { for }}, t_{\text {for }}^{\text {per }}$ - time of breaking and making up transfers.

Time of rolling stock breaking up is:

$$
t_{i \check{s} \text { for }}=A g_{a t}+B \frac{Q_{p}\left(1+t_{\beta} \gamma\right)}{P_{b r}},
$$

here $A, B$ - coefficients depending on shunting conditions; $\gamma$-variability coefficient of the number of uncouplings in transfers: $\gamma=0,1-0,3 ; g_{a t}$-number of uncouplings in transfers.

The number of uncouplings in a single rolling stock, when wagons are not formed beforehand, may be obtained from the formula [5]:

$$
g_{a t}=\left(1-\sum_{j=1}^{C} \frac{m_{j}}{\bar{m}_{p}} \cdot \frac{m_{j}-1}{\bar{m}_{p}-1}\right)\left[\bar{m}_{p}\left(1+t_{\beta} \gamma\right)-1\right] \alpha_{s t},
$$

here $m_{j}$ - number of wagons in the $j$-th destination rolling stock.

$$
\left(\sum_{j=1}^{C} m_{j}=\bar{m}_{p}\left(1+t_{\beta} \gamma\right)\right)
$$

$C$ - number of wagons in the above rolling stock (equivalent to the number of loading points at the station but not exceeding the number of wagons in the train); $\alpha_{s t}$ - coefficient of group enlargement: $\alpha_{s k}=0,3-0,4 ; \bar{m}_{p}$-average number of wagons in a rolling stock:

$$
\bar{m}_{p}=\frac{Q_{p e r}}{P_{b r}} .
$$

Time of making up one group of wagons to be transferred to the railway sorting yard at the shipment terminal is:

$$
t_{\text {for }}^{p a d}=0,07 n_{a t k}+\left(0,04+0,19 n_{a t k}\right) \frac{Q_{p}\left(1+t_{\beta} \gamma\right)}{P_{b r} 30 N_{a t k}},
$$

here $n_{a t k}$ - average number of uncouplings in the transfer group being made up.

Time expenditures in making up trains are:

$$
t_{\text {for } . i}=\left(a+b m_{r_{i}}\right) r_{i} \frac{1}{60},
$$

here $m_{r_{i}}$-number of wagons to be transferred in making up the train for the $i$-th shunting area:

$$
m_{r_{i}}=\frac{Q_{p}\left(1+t_{\beta} \gamma\right)}{P_{b r} N_{a t k} m_{r}^{k r}},
$$

where $m_{r}^{k r}$-number of sorting tracks at the shipment terminal; $r_{i}$-number of transfers needed to make up the train for the $i$-th destination on $m_{r}^{k r}$ tracks:

$$
r_{i}=2 m_{r}^{k r}+2\left[g_{c i}\left(C_{i}^{l}-m_{r}^{k r}\right) \frac{1}{C_{i}^{l}}\right],
$$

where $g_{c i}$-number of uncouplings used to from a group of wagons:

$$
g_{c i}=\frac{m_{\text {pas. } i}\left(C_{i}^{l}-1\right)}{C_{i}^{l}},
$$

$C_{i}^{l}$ - number of destinations for a group of wagons sent to $i$-th region (equal to the number of loading points in the $i$-th shunting region, but not exceeding the number of wagons in a group $\left.m_{\text {pas. } i}\right) ; m_{\text {pas. } i}-$ number of wagon groups for the $i$-th destination.

$$
m_{\text {pas. } i}=\frac{\bar{m}_{k r i}^{p a d}}{x_{i}},
$$

where $\bar{m}_{k r i}^{\text {pad }}$ - average number of wagons for the $i$-th shunting area; $x_{i}$ - number of wagon groups driven up to the $i$-th shunting area.

If a shipment terminal sends wagons to a sorting yard without the preliminary formation, then:

$$
t_{u \check{z} . \text { išs }}=t_{\text {t.o }}^{o}+\frac{1}{K} \sum_{j=1}^{k} t_{\text {lau.per.j }}
$$

here $t_{t . o}^{o}$ - time of rolling stock handling at a dispatching station; $t_{\text {lau.per. } j}$ - average waiting time for rolling stock dispatching from the shipment yard:

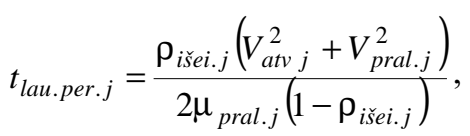


here $V_{a t v j}, V_{\text {pral.j }}$ - coefficients of rolling stock dispatching and passing intervals limited by the $j$-th exit track element; $\rho_{i \check{s} e i . j}-$ load of the $j$-th exit track:

$$
\rho_{i \check{s} e i . j}=\rho_{o j}+\frac{N_{p e r . j} t_{j}^{\min }}{24},
$$

$\rho_{o j}$ - the $j$-th track load not taking into account train handling operations; $N_{\text {per. } j}$ - number of rolling stocks sent to the $j$-th track (per cent of $N_{p e r}$ ); $t_{o j}^{\min }$ - allowable technological time interval of trains departure from the $j$-th exit, $\mathrm{h} ; \mu_{\text {pral. } j}$ - intensity of passing trains through the $j$-th exit.

The number of tracks needed for keeping wagons till they are made up and depart may be calculated from the formula:

$$
m_{\text {st.kr } c}=\frac{2 \sum_{i=1}^{m} x_{i}\left(t_{\text {tech }}^{\text {pad }}\right)+t_{\text {lau.pad } .-n u}}{T_{\text {pad }}\left(1-t_{\beta} \gamma_{\text {pad }}\right)},
$$

here $t_{\text {tech }}^{\text {pad }}$ - technological time, needed for the locomotive driving in, coupling of a group of wagons, applying the brakes, etc.; $T_{\text {pad }}$ - time of locomotive operation in driving the wagons in and out: for 24 hours of operation $-T_{\text {pad }}=24-\sum T_{\text {past }} ; \gamma_{\text {pad }}-$ variability coefficient of the interval of driving in groups of wagons; $\gamma_{\text {pad }}=0,2-0,4 ; t_{\text {lau.pad.-nu }}-$ average waiting time for wagons grouping/driving out from the side-tracks to a shipment yard:

$$
t_{\text {lauk.pad. }-n u}=\frac{12 \rho_{l}^{2}\left(\gamma_{i \check{s} s t}^{2}+\gamma_{p a d}^{2}\right)}{\sum x_{i}\left(1-\rho_{l}\right)},
$$

$\gamma_{i \check{s} s t}-$ variability coefficient of the interval of wagons making up and driving out from the yard by a sidetrack to and from the station.

The number of tracks at shipment terminals not provided with gravity humps is obtained by minimizing the costs of road maintenance and construction, delaying of wagons and shunting operations. In general overall costs are calculated from the formula:

$E_{c}=\left[\left(T_{i s ̌ o r}+T_{f o r}\right)\left(e_{l .-h}+e_{v .-h} \bar{m}_{k r e}\right)\right] 365 N_{p e r}+E_{p} m_{r}^{k r},($

here $T_{i \check{s} f o r}$ - time of rolling stock breaking up; $T_{\text {for }}-$ time of wagons making up into groups $E_{p}$ - total costs of construction and maintenance of sorting tracks; $m_{r}^{k r}-$ number of sorting tracks; $e_{l .-h}-$ cost of locomotive operation per hour; $e_{v .-h}-$ cost of wagon use per hour.

The larger the number of sorting tracks, the higher the time of train breaking up and construction and maintenance costs and the lower the time making up of rolling stocks.
Therefore, the optimal number of tracks may be found by differentiating the expression (18) according to the number of tracks. The tests performed show that the optimal number of sorting tracks while minimizing the total costs may be obtained from the formula:

$$
\begin{aligned}
& m_{r}^{k r}=1+\sqrt{\frac{365 N_{p e r}\left(e_{l .-h}+e_{v .-h} \bar{m}_{k r c}\right) \times}{730 N_{p e r}\left(e_{l .-h}+e_{v .-h} \bar{m}_{k r c}\right) \times}} \\
& \frac{\left(2 A(C-1)+\left(C^{2}-1\right) m_{k r c} B\right)}{\left(E+D \bar{m}_{k r c}\right)+2 E_{p}}
\end{aligned}
$$

here $A, B, E, D$-parameters specified by the instructions for standard shunting operations, $h$.

In general, in sorting the wagons on a side-track with a slope less than $1,5 \%, A=0,3 ; B=0,0023$; $E=0,03 ; D=0,0005$. If shunting is performed at isolated points, then $A=0,025 ; B=0,0017$.

Total costs of construction and maintenance of a sorting track are as follows:

$$
E_{k}=E_{n}\left(k_{k} l_{r}+n_{i e \check{s}} K_{i e \check{s}}\right)+E_{l} l_{r}+E_{i \check{s} l} n_{i e \check{s}},
$$

here $E_{n}$ - specified coefficient of capital investment efficiency; $k_{k}$ - cost of $1 \mathrm{~km}$ track construction, taking into account cost of earth moving; $l_{r}$ - sorting track length, km; $n_{i e \check{s}}-$ number of switches on a track; $K_{i e \check{s}}$ - cost of switch installation and starting up; $E_{l}-$ relative costs of maintaining $1 \mathrm{~km}$ track, $E_{i \check{L} l}-$ maintenance costs of a switch.

The length of a sorting track is calculated by the formula:

$$
l_{r}=\frac{\bar{m}_{k r c}\left(1+3 \gamma_{p a d}\right) l_{v}}{\sum x_{i}} \geq 200,
$$

where $\gamma_{\text {pad }}-$ coefficient of the number of wagons in a group: $\gamma_{\text {pad }}=0,3-0,4$.

The larger the number of sorting tracks, the higher the time of train breaking up and construction and maintenance costs and the lower the time of making up rolling stocks. The number of tracks for breaking and making up rolling stocks at the stations with gravity humps is calculated according to the minimum total costs:

$$
\begin{aligned}
& E_{b}=365\left[N_{\text {per }} t_{i s ̌ f o r}^{k r}\left(e_{l,-h}+e_{v \cdot-h} m_{p e r}\right)+\right. \\
& \left.\sum x_{i} t_{f o r}\left(e_{l \cdot-h}+e_{v \cdot-h} \bar{m}_{p a d}\right)\right]+E_{k}^{k r} m_{r}^{k r} \rightarrow \min .
\end{aligned}
$$

The time of rolling stock breaking up when a gravity hump is used is equal to:

$$
t_{i s ̌ f o r}^{k r}=\left(t_{u \check{z} v a \check{z}}+t_{i \check{s} s t}+t_{\text {pritr }}+t_{\text {pal }}+t_{\text {sust }}\right) \frac{1}{60},
$$

where $t_{u \check{z} v a \check{z}} ; t_{i \check{s} s t} ; t_{\text {pritr }} ; t_{\text {pal }} ; t_{\text {sust }}$ - time of rolling 
stock driving in, making up, starting and stopping, respectively. Time of breaking up the train is determined depending on the type of the gravity hump. For a station with a mechanized gravity hump it is as follows:

$$
\begin{aligned}
& t_{p a l}=\left(\frac{0,03 l_{v}}{4,49 \alpha_{s t}+0,52}\right) \times \\
& \left(\frac{m_{r}^{k r}\left(2 \frac{\bar{m}_{k r c}}{N_{p e r}} \alpha_{s t}-1\right)-2 \frac{m_{k r c}}{N_{p e r}} \alpha_{s t}}{m_{r}^{k r}-1}\right) .
\end{aligned}
$$

If a gravity hump is not automated, then:

$$
\begin{aligned}
& t_{p a l}=\left(\frac{0,03 l_{v}}{2,905 \alpha_{s t}+0,535}\right) \times \\
& \left(\frac{m_{r}^{k r}\left(2 \frac{\bar{m}_{k r c}}{N_{p e r}} \alpha_{s t}-1\right)-2 \frac{\bar{m}_{k r c}}{N_{p e r}} \alpha_{s t}}{m_{r}^{k r}-1}\right) .
\end{aligned}
$$

Time of rolling stock making up at side-tracks is as follows:

$$
\begin{aligned}
& t_{f o r}=\frac{1}{60}\left(a+b \frac{\frac{\bar{m}_{k r c}}{N_{p e r}}+\frac{m_{k r c}}{\sum x_{i}}}{2\left(m_{r}^{k r}-1\right)}\right) \times \\
& \left(2 m_{k r c}+\frac{2 \frac{m_{k r c}}{\sum x_{i}} \alpha_{s t}\left(C_{k}-1\right)\left(C_{k}-m_{k r c}\right)}{C_{k}^{2}}\right),
\end{aligned}
$$

here $\alpha_{s t}$ - enlargement coefficient of the number of uncouplings; $C_{k}$ - number of destinations of a made up rolling stock.

Costs of construction and maintenance of one track of a sorting yard in a general shipment terminal are as follows:

$$
E_{k}^{k r}=E_{n}\left(C_{k} l_{r k}+2 C_{i e \check{s}}+\frac{C_{k a l}}{m_{r}^{k r}}\right)+\frac{P_{k a l}}{m_{r}^{k r}}+P_{k} l_{r k}+2 P_{i e \check{s}},
$$

where $E_{n}$-standard coefficient of capital investment efficiency; $C_{k}, C_{i e \check{s}}-$ cost of $1 \mathrm{~km}$ track construction and cost of a switch; $P_{k}, P_{i e \check{s}}$-yearly maintenance cost of $1 \mathrm{~km}$ track and a switch; $l_{r k}$-track length in a sorting yard, $\mathrm{km}$.

Cost of gravity hump construction is:

$$
C_{k a l}=f_{1}+f_{2} m_{r}^{k r},
$$

here $f_{1}, f_{2}$-coefficients based on the statistical data about the mechanization degree of a gravity hump and the cost of construction.

Yearly costs of gravity hump maintenance are:

$$
P_{k a l}=\varphi_{1}+\varphi_{2} m_{r}^{k r},
$$

here $\varphi_{1}, \varphi_{2}$-coefficients based on the statistical data on the gravity hump maintenance cost.

By substituting the values $t_{i s ̌ o r}, t_{\text {for }}$ and $E_{k}^{k r}$ into the formula (19) an optimal $m_{r}^{k r}$ value is obtained. For a station with a mechanizsed gravity hump it is expressed in this way:

$$
\begin{aligned}
& m_{r}^{\text {mech }}=1+\sqrt{\frac{\frac{N_{p e r} B\left(e_{l-h}+e_{v .-h} \bar{m}_{p a d}\right)\left(\bar{m}_{p a d}+\bar{m}_{p e r}\right)}{60} \times}{\frac{1}{365}\left[E_{n}\left(\frac{\bar{m}_{k r c} C_{k}}{2000 \sum x_{i}}+2 C_{i e \check{s}}+f_{2}\right)+\right.}} \\
& \overline{\left(1+\frac{\bar{m}_{p a d}\left(C_{k}-1\right)^{3}}{\left(\bar{m}_{p a d}-1\right) C_{k}^{2}}\right)-} \\
& \overline{\left.\left(\varphi_{2}+2 P_{i e \check{s}}+\frac{P_{k} \bar{m}_{k r} l_{v}}{2000 \sum x_{i}}\right)\right]+} \\
& \frac{\frac{N_{p e r} l_{v}\left(e_{l,-h}+\bar{m}_{p e r} e_{v,-h}\right)\left(m_{p e r}-1\right)}{2000\left[4,49\left(C_{k}-1\right)+\left(\bar{m}_{p e r}-1\right) 0,52\right]}}{\frac{a \sum x_{i}\left(e_{l,-h}+e_{v,-h} \bar{m}_{p a d}\right)}{30}\left(1-\frac{\bar{m}_{p a d}\left(C_{k}-1\right)^{2}}{\left(\bar{m}_{p a d}-1\right) C_{k}^{2}}\right)} .
\end{aligned}
$$

The number of sorting tracks for a station provided with a non-mechanized gravity hump is obtained in a similar way. The total number of tracks in a sorting yard is found from the formula:

$$
m_{c}^{b}=m_{c}+m_{k . f o r}+m_{s p . k},
$$

here $m_{c}-$ number of tracks required for optimal making and breaking up groups of wagons; $m_{k . f o r}-$ number of tracks required for rolling stock making up according to plan (compound or special route trains, etc.); $m_{s p . k}$ - number of special tracks. 


\section{Determining of an optimal number of wagons for shunting rolling stocks}

An optimal number of wagons in a transfer group is determined taking into account:

- costs of wagons idle time including the period of gathering the required number of wagons for making up an adequate group per 24 hours:

$$
N_{v \cdot-h}=\frac{24 m}{X_{p e r}} k e_{v \cdot-h}
$$

here $m$ - number of wagons going to the seaport; $X_{p e r}$ - number of transfers; $k$-coefficient evaluating the type of wagon gathering;

- costs of wagon idle time until departure per 24 hours:

$$
N_{v .-h}^{n u \dot{e}}=\left(\frac{24 m}{X_{p e r}}-T_{k r}\right) m e_{v .-h},
$$

here $T_{k r}$ - time of shipment;

- costs of the shunting locomotive operation per 24 hours;

$$
N_{l .-h}=X_{p e r}\left(t_{t e c h}+2 t_{j u d}\right) e_{l .-h},
$$

here $t_{\text {tech }}$ - time of technical operations; $t_{j u d}-$ time of train running; $e_{v .-h}, e_{l .-h}-$ operational cost of a wagon and a locomotive hour, respectively.

An optimal interaction mode of grouping the wagons, when the total cost value is minimum:

$$
\begin{aligned}
& E=C_{v \cdot-h} \sum N_{v \cdot-h}+e_{l-h} N_{l-h} \rightarrow \min , \\
& E=\left(\frac{24}{X_{p e r}} k+\frac{24}{X_{p e r}}-T_{k r}\right) m e_{v \cdot-h}+ \\
& X_{p e r} e_{l .-h}\left(t_{\text {tech }}+2 t_{j u d}\right) .
\end{aligned}
$$

To find the minimum value of the function $E=f\left(X_{p e r}\right)$, let us differentiate

$$
\frac{d E}{d X_{p e r}}=e_{l .-h}\left(t_{\text {tech }}+2 t_{j u d}\right)-\left(\frac{24 k}{X_{p e r}^{2}}+\frac{24}{X_{p e r}^{2}}\right) m e_{v .-h} .
$$

Because the second derivative $\frac{d^{2} E}{d X_{p e r}^{2}}>0$, when

$$
X_{p e r}=\sqrt{\frac{24(k+1) m e_{v \cdot-h}}{e_{l,-h}\left(t_{\text {tech }}+2 t_{j u d}\right)}}
$$

the value of function (26) will be minimum.

For example, 100 wagons of a non-routed flow arrive at the seaport. The distance of the port from the station is $6 \mathrm{~km}$, the speed on the approach roads $30 \mathrm{~km} / \mathrm{h}$; time of technical operations $-1,2 \mathrm{~h}$, a wagon hour costs 0,1 conventional units and the cost of loco- motive hours -7 conventional units.

The optimal number of transfer operations is obtained from the formula (27), according to which

$$
X_{\text {per }}=\sqrt{\frac{24(0,4+1) 100 \times 0,1}{7\left(1,2+2 \frac{6}{30}\right)}} \approx 5 \text { transfers. }
$$

When solving problems of finding an optimal transfer number in the case of queues, it is specified that time expenditures of the locomotive should not exceed the value $T_{1}$. These problems are usually solved by the Lagrange multipliers approach. An objective function in the problem of determining the number of transfers to the port or approach roads will be:

$$
\begin{aligned}
& E=\sum_{p=1}^{l} e_{v \cdot-h} m_{p}\left(\frac{24}{X_{p e r}^{p}} k+\frac{24}{X_{p e r}^{p}}-T_{k r}\right)+ \\
& \sum_{p=1}^{l} e_{l .-h} X_{p e r}^{p}\left(t_{t e c h}^{p}+2 t_{j u d}^{p}\right) \rightarrow \min .
\end{aligned}
$$

A constraint is as follows:

$$
\sum_{p=1}^{l} X_{p e r}^{p}\left(t_{t e c h}^{p}+2 t_{j u d}^{p}\right)=T_{l}
$$

here $l$ - number of points at the railway terminal to which wagon groups are driven in.

Let us generate a Lagrange function for the expression (28):

$$
\begin{aligned}
& \varphi\left(X_{p e r}^{1}, X_{p e r}^{2}, \ldots, X_{p e r}^{l}, \alpha\right)= \\
& e_{v \cdot-h} \sum_{p=1}^{l} m_{p}\left(\frac{24(k+1)}{X_{p e r}^{p}}-T_{k r}\right)+ \\
& e_{l .-h} \sum_{p=1}^{l} X_{p e r}^{p}\left(t_{\text {tech }}^{p}+2 t_{j u d}^{p}\right)+ \\
& \alpha_{1}\left(\sum_{p=1}^{l} X_{p e r}^{p}\left(t_{\text {tech }}^{p}+2 t_{j u d}^{p}\right)-T_{l}\right) .
\end{aligned}
$$

An equality system after differentiating the expression (29) will be of the form:

$$
\begin{aligned}
& \frac{d \varphi\left(X_{p e r}^{1}, X_{p e r}^{2}, \ldots, X_{p e r}^{l}, \alpha_{1}\right)}{d X_{p e r}^{l}}=e_{l .-h}\left(t_{\text {tech }}^{p}+2 t_{j u d}^{p}\right)- \\
& {\left[\frac{24}{X_{p e r}^{p^{2}}}(k+1)\right] m_{p} e_{v .-h}+\alpha_{1}\left(t_{\text {tech }}^{p}+2 t_{j u d}^{p}\right),}
\end{aligned}
$$


from this

$$
X_{p e r}^{p}=\sqrt{\frac{24(k+1) m_{p} e_{v \cdot-h}}{e_{l .-h} t_{0}^{p a d}+\alpha t_{o}^{p a d}}} .
$$

By multiplying the left and right sides of the equation (30) by $t_{o}^{\text {pad }}$ and by summing up according to $p$, we will get

$$
\sum_{p=1}^{l} X_{p e r}^{p} t_{o}^{p a d}=\sum_{p=1}^{l} \sqrt{\frac{24(k+1) m_{p} e_{v \cdot-h} t_{o}^{p a d}}{e_{l-h} t_{o}^{p a d} \alpha_{1}}},
$$

or

$$
T_{l}=\sum_{p=1}^{l} \sqrt{\frac{24(k+1) m_{p} e_{v .-h} t_{o}^{p a d}}{e_{l .-h}+\alpha_{1}}},
$$

and after the appropriate rearrangements we will obtain the expression for $X_{p e r}^{p}$ :

$$
X_{p e r}^{p}=\frac{T_{l} \sqrt{\frac{m_{p}}{t_{o}^{p a d}}}}{\sum_{p=1}^{l} \sqrt{m_{p} t_{o}^{p a d}}} .
$$

Example. The number of transfers to the port and two approach roads where one locomotive runs should be determined. The locomotive operation time is 22,6 $\mathrm{h}$, cost of wagon hour is 0,1 convent. units, cost of locomotive hour -7 convent. units.

The parameters of calculations are given in Table.

Calculation parameters of loading/unloading points

\begin{tabular}{|llll|}
\hline Loading/unloading point & $m$ & $t_{\text {tech }}, \mathrm{h}$ & $t_{\text {jud }}, \mathrm{h}$ \\
\hline PK No l & 100 & 1,2 & 0,2 \\
\hline PK No 2 & 120 & 2,0 & 0,3 \\
\hline Port & 200 & 1,0 & 0,2 \\
\hline
\end{tabular}

The formula (31) is used to determine the optimal number of transfers. According to it we get:

$$
\begin{aligned}
& X_{\text {per }}^{p_{K 1}}=\frac{22,6 \sqrt{\frac{100}{1,6}}}{\sqrt{100 \times 1,6}+\sqrt{120 \times 2,6}+\sqrt{200 \times 1,4}} \approx 4, \\
& X_{\text {per }}^{p_{K 2}} \approx 3 ; X_{\text {per }}^{p_{\text {uostas }}} \approx 6 .
\end{aligned}
$$

When the locomotive time reserve is reduced to $19,6 \mathrm{~h}$, an optimal transfer number is equal to:

$$
X_{p e r}^{p_{K 1}} \approx 3 ; X_{p e r}^{p_{K 2}} \approx 3 ; X_{p e r}^{p_{u o s t a s}} \approx 5 \text {. }
$$

Therefore, when reducing the locomotive time reserve, it is necessary to reduce the transfers to PK1 and the port, maintaining the same level of servicing at PK2.

\section{Conclusions}

1. The tests made allowed us to identify the major factors having an impact on the integrated technological process management at the terminal.

2. By minimizing the costs of road construction and maintenance, as well as the delay time of wagons and costs of shunting operations, an optimal number of tracks at the shipment terminals provided or not provided with gravity humps has been determined.

3 . By minimizing costs of wagon idle time per 24 hours due to wagons gathering, dispatching and the locomotive shunting, an optimal number of wagons has been calculated for the shunting rolling stocks.

\section{References}

1. Guelat, J.; Florion, M.; Crainic, T.-G. A Multimode Multiproduct Network Assignment Model for Strategic Planning of Freight Flows. Transportation Science, Vol 24, No 1, February, 1990, p. 25-39.

2. Zhan, F.-B.; Noon, Ch.-F. Shortest Path Algorithms: An Evaluation using Real Road Networks. Transportation Science, Vol 32, No 1. February, 1998, p. 65-73.

3. Nuzzolo, A.; Russo, F.; Crisali, U. A Doubly Dynamic Schedule-based Assignment Model for Transit Network. Transportation Science, Vol 35, No 3, August, 2001, p. 268-285.

4. Bodin, L.; Mingozzi, A.; Baldacci, R.; Ball, M. The Roll on - Roll off Vehicle Routing Problem. Transportation Science, Vol 34, No 3, August, 2000, p. 256-271.

5. Baublys, A. Strategic planning of railway freight carriage. Transportas, Vol XIV, No 5, Vilnius: Technika, 1999, p. 209-214. ISSN 1648-1442.

6. Baublys, A. Modelling shipment operations at the terminal. Transport Engineering (Transportas), Vol XV, No 3, Vilnius: Technika, 2000, p. 105-108. ISSN 16484142.

7. Povorozhenko, V. Interaction of various transport facilities and container carriage (Взаимодействие разного транспортного оборудования и контейнерных перевозок). Moscow: Transport, 1990. 348 p. (in Russian).

8. Gruntov, P. S. Management problems of maintenance and quality of tranpsortation (Управление проблемами обслуживания и качества перевозок). Moscow: Transport, 1994. 543 p. (in Russian). 